\title{
ATENDIMENTO PEDAGÓGICO DOMICILIAR: UMA INTERVENÇÃO CRÍTICO- REFLEXIVA NA FORMAÇÃO DE PROFESSORES ${ }^{25}$ HOME PEDAGOGICAL CARE: A CRITICAL - REFLECTIVE INTERVENTION TRAINING
}

\author{
Giovanna Mara Ciampi Costa Barroso 26 \\ Paulo Pires de Queiroz ${ }^{27}$
}

\begin{abstract}
RESUMO
A investigação objetivou organizar um minicurso crítico-reflexivo sobre o Atendimento Pedagógico Domiciliar que seja voltado a professores atuantes com alunos público-alvo da Educação Especial inclusiva num município da região da Zona da Mata de Minas Gerais. Para o alcance do objetivo, adotou-se um modelo metodológico organizado em etapas de diagnóstico, intervenção e avaliação. A organização da atividade respondeu à demanda de informar o professor da educação especial sobre a importância da inclusão e da reflexividade crítica na construção de um APD eficaz, pensado para uma escola humanística. Espera-se que este estudo possa contribuir a um lacunar estado da arte sobre uma importante, porém ainda pouco conhecida, modalidade de ensino inclusivo. Palavras-chave: Atendimento pedagógico domiciliar. Reflexividade Crítica. Docência escolar. Inclusão.
\end{abstract}

\section{ABSTRACT}

The research aims to design a critical-reflexive mini-course about Home Pedagogical Care (HPC) with teachers working with students targeting inclusive special education in a Minas Gerais town. This way, a methodological model was adopted, organized in stages of diagnosis, intervention and evaluation. The activity responded to the demand to inform the teachers about the importance of inclusion and critical reflexivity in the construction of a humanistic HPC. This study may contribute to the state of the art about an important, but still little known, inclusive school-education modality.

Keywords: Home teaching care. Critical Reflection. School Teaching. Inclusion.

\footnotetext{
${ }^{25}$ Artigo elaborado com base na pesquisa de mestrado concluída pelo CMPDI/ UFF, sob a orientação do professor Dr. Paulo Pires de Queiroz

${ }^{26}$ Mestre em Diversidade e Inclusão - CMPDI - UFF, Psicopedagoga, Professora AEE e Atendimento Pedagógico Domiciliar Prefeitura de Juiz de Fora - MG. E-mail: giovannaciampibarroso@hotmail.com. Telefone: (32) 99909-7373

${ }^{27}$ Cientista Social e PhD em Filosofia e Humanidades. Professor e Pesquisador Adjunto do Departamento Sociedade, Educação e Conhecimento - SSE, na Faculdade de Educação, da Universidade Federal Fluminense - UFF. E-mail: ppqueiroz@yahoo.com.br. Telefone: (21) 99767-7102
} 


\section{RevistAleph}

\section{Introdução}

A formação crítico-reflexiva dos professores da escola básica é um debate bastante conhecido. Cada vez mais, a educação inclusiva tem emergido como uma pauta nesse espaço. No entanto, quando o Atendimento Pedagógico Domiciliar - APD é chamado à discussão, o cenário é outro. Prevista em lei, essa modalidade de ensino básico ainda tem sido pouco explorada por estudos acadêmicos e políticas públicas no país.

A legislação brasileira desde 1969, com a publicação do Decreto Lei 1044/ 1969, propõe a educação de estudantes que se encontram impedidos de frequentar a escola comum por motivo de tratamento de saúde, não hospitalizados. Nessa direção, as gestantes a partir do oitavo mês de gravidez e durante três meses subsequentes (pósparto), também deveriam usufruir desse Direito, pois são contempladas no Decreto 1044, Lei no. 6.202, de 17 de abril de 1975; surgindo aí a figura institucional do Atendimento Pedagógico Domiciliar (APD).

O APD é ressignificado na ordem institucional fundada em 1988, com a promulgação da Constituição Federal do Brasil. No espírito da educação como "direito de todos e dever do Estado e da Família" (Art. 205), emergem legislações que preveem o desenvolvimento de ações integradas para promover a universalização e o acesso ao atendimento educacional, mesmo para aqueles que não podem frequentar uma escola. Gradualmente, o APD é compreendido como o braço de uma educação especial de caráter potencialmente inclusivo, em documentos institucionais como o Estatuto da Criança e do Adolescente (Art 5ㅇ) , a Lei de Diretrizes e Bases da Educação Nacional, de 1996 (Art. 58, § 2ㅇ) e, anos mais tarde, Classe hospitalar e atendimento pedagógico domiciliar: Estratégias e orientações, material editado pelo MEC (2002).

Nesse importante, porém pouco explorado, âmbito, este artigo objetiva apresentar uma parte dos resultados de uma pesquisa desenvolvida acerca do Atendimento Pedagógico Domiciliar (APD) num município de Minas Gerais que teve como propósito Organizar um minicurso crítico-reflexivo com o tema Atendimento Pedagógico Domiciliar (APD) que seja voltado a professores atuantes com alunos público-alvo da Educação Especial inclusiva. 


\section{RevistAleph}

Por meio de um desenho metodológico composto por movimentos de diagnóstico, intervenção e avaliação, buscou-se alcançar o objetivo do estudo, levantando achados e conclusões significativas ao estado da arte. Este artigo relata o percurso deste recorte da investigação, em quatro momentos analíticos: fundamentação teórica, materiais e métodos, resultados e discussão.

\section{O Atendimento Pedagógico Domiciliar: campo inclusivo e crítico-reflexivo}

Segundo as diretrizes do MEC (Brasil, 2002), para a qualidade do APD o professor precisa estar integrado ao sistema de saúde, e o diálogo entre os profissionais da educação e da saúde precisa ser constante, para que haja uma proteção da saúde do aluno: não basta ao estudante ter as aulas, estas devem estar em sintonia com as singularidades de seu estado de saúde. Ainda de acordo com as orientações do MEC 2002, o professor é responsável por propor os procedimentos didático-pedagógicos e as práticas alternativas de modo a otimizar o processo ensino-aprendizagem dos alunos acamados. Assim, a formação adequada do professor que fará o atendimento domiciliar é fundamental para que esse processo se estabeleça. De acordo com tais orientações:

O professor deverá ter a formação pedagógica preferencialmente em Educação Especial ou em cursos de Pedagogia ou licenciaturas, ter noções sobre as doenças e condições psicossociais vivenciadas pelos educandos e as características delas decorrentes, sejam do ponto de vista clínico, sejam do ponto de vista afetivo. Compete ao professor adequar e adaptar o ambiente às atividades e os materiais, planejar o dia-a-dia da turma, registrar e avaliar o trabalho pedagógico desenvolvido (BRASIL, 2002).

Nessa modalidade educacional é preciso levar em consideração as mais diferenciadas situações a que estão expostos tanto o aluno quanto o educador que faz o atendimento, visto toda a sua singularidade em relação ao sistema escolar regular e mesmo em relação ao atendimento especializado. Embora o aluno receba o atendimento pedagógico domiciliar, é importante despertar nele o sentimento de pertencimento à escola. Assim, a integração do discente com a comunidade escolar é um ponto que deve ser considerado já que pode estimular e ressignificar a 


\section{RevistAleph}

aprendizagem. Para tanto, o professor da escola básica poderá estar preparado para responder aos desafios de um APD que, numa sociedade democrática, cada vez mais requer ser compreendido em sentido inclusivo. É a partir desta premissa que concebemos o Atendimento Pedagógico Domiciliar.

Com efeito, o APD que pensamos está fundamentado nas perspectivas da inclusão e da docência crítico-reflexiva. Consideramos estes dois pilares interdependentes e indispensáveis à proposta que desenhamos.

Partimos de uma concepção da inclusão que a admite como mais do que prestação de serviços, mais do que um favor e mais do que a observância cega da lei: trata-se de uma questão de Direitos Humanos (Queiroz, 2018; Stainback e Stainback, 1999). Pessoas que incluem tornam-se seres humanos melhores. Uma sociedade melhor, mais afeita à tolerância e ao respeito às diferenças, pode e deve ser construída a partir de uma educação de caráter inclusivo.

Destacamos que "a razão mais importante para o ensino inclusivo é o valor social da igualdade". (Karagiannis; Stainback; Stainback, 1999, p.27). Todos nós temos o mesmo direito à educação, de participar de sua construção coletiva na escola. Questionando a perspectiva segregacionista que tradicionalmente marca a sociedade e a escola, a inclusão reforça a prática da ideia de que as diferenças precisam ser aceitas e respeitadas. Segundo Karagiannis, Stainback e Stainback (1999), devemos ensinar os alunos através do exemplo de que, apesar das diferenças, todos nós temos direitos iguais. Desse modo, em contraste com as experiências passadas de segregação, a educação inclusiva reforça a prática da ideia de que as diferenças deveriam ser aceitas e respeitadas nos espaços escolares.

De acordo com Karagiannis; Stainback; Stainback (1999, P.48), educando todos os alunos juntos, as pessoas com deficiências têm oportunidade de preparar-se para a vida na comunidade, os professores melhoram suas habilidades profissionais e a sociedade toma a decisão consciente de funcionar de acordo com o valor social da igualdade para todas as pessoas, com os consequentes resultados de melhora da paz social.

Além disso, quando existem programas adequados, a inclusão funciona para 


\section{RevistAleph}

todos os alunos com e sem deficiências, em termos de atitudes positivas, mutuamente desenvolvidas, de ganhos nas habilidades acadêmicas e sociais e de preparação para a vida na comunidade (Karagiannis; Stainback; Stainback, 1999, P. 244).

Para que a escola seja de fato inclusiva, vale ressaltar que são necessárias ações cooperativas e trabalho em grupo dos profissionais. Apenas desse modo será possível construir de forma satisfatória um currículo oculto que pense totalidade, hegemonia e ideologia, possibilitando aos discentes Aprendizagens Cooperativas, onde eles ajudemse mutuamente, através de mediações pedagógicas desenvolvidas pelos professores. Um ambiente educativo como tal pode proporcionar aos alunos com deficiência uma vida autônoma, interação com seus pares e professores, contribuindo de forma positiva para toda a sociedade.

Igualmente, redes de apoio e trabalho em equipe são fundamentais ao sucesso de um ensino inclusivo (STAINBACK e STAINBACK, 1999, p.74). Tal trabalho nunca pode ser entendido como um exercício individualista, mas sempre relacional, em que o docente deve estar em articulação constante com todos os profissionais que trabalham com os seus alunos.

O professor crítico-reflexivo é a contrapartida desse tipo de educação que estamos a tratar. Esse profissional se caracteriza pela criatividade e capacidade de questionamento de sua atuação, construindo e ressignificando conhecimentos que lhe permitam aperfeiçoá-la paulatinamente. No campo do APD, urge que o professor esteja apto a mobilizar os saberes e estratégias que possibilitem oferecer uma educação inclusiva de qualidade. Nenhuma rede de apoio nem equipe pedagógica comprometida com a inclusão pode subsistir sem ele.

Sem dúvida, a formação para a docência necessita de um currículo que contemple a razão de ser professor num novo modelo de sociedade que abarque a inserção de diferentes sujeitos aprendizes em ambientes repletos de peculiaridades especiais e, com contextos que valorizem e fortaleçam a crença local. Contudo, é notória, de acordo com um vasto debate acadêmico há algumas décadas (Alarcão, 1996; Nóvoa, 2011; Pimenta e Ghedin, 2012; Queiroz, 2012; Tardif, 2005), a dominância de um currículo tecnicista na formação do professor, desvinculado dos diferentes 


\section{RevistAleph}

contextos escolares, sociais, culturais e pessoais nos quais a docência escolar se processa. A este modelo, a autora contrapõe um paradigma crítico-reflexivo de qualificação docente.

Para tanto, a autora parte de uma revisão conceitual e fundamentação nos trabalhos do norte-americano Donald Schön, o principal formulador e influenciador da discussão contemporânea que trata dos conceitos professor reflexivo e professor pesquisador. Segundo Schön (2000 apud PIMENTA 2012), a prática reflexiva deve estar ancorada nos conceitos de reflexão na ação, reflexão sobre a ação e reflexão sobre a reflexão na ação. Nessa direção, segundo a reflexão na ação, aponta-se a alternativa de reflexão durante a ação, sem interrompê-la, volta-se para dar nova forma ao que se está fazendo, enquanto ainda o faz. Para Schön (2000), o profissional capacitado para refletir sobre a sua prática e na sua prática é quem está preparado para propor respostas aos problemas de seu cotidiano laboral.

Mas como trabalhar com a ideia de uma educação inclusiva com uma noção de reflexividade individualista como a de Schön? Não faz sentido. Numa outra direção, a reflexividade crítica emerge como uma alternativa capaz de possibilitar a construção coletiva e plural dos saberes profissionais que docência escolar necessita (Nóvoa, 2011; Pimenta e Ghedin, 2012, Tardif, 2010).

Cabe, sim, afirmar a reflexividade crítica na docência como um exercício de tomada de consciência e questionamento que os professores fazem quanto às condições e implicações sociais do seu trabalho na escola. Um exercício que os permite experimentar e avaliar melhorias nas práticas educativas, que façam delas mais democráticas e emancipatórias. Perceba que as ideias de reflexão "sobre a ação" e "na ação" estão presentes, entretanto, ao contrário do que Schön propõe, elas são entendidas sempre numa perspectiva coletivista. Nosso foco é, assim, no profissional do APD como um ator crítico-reflexivo, um agente fundamental para a construção de uma escola inclusiva.

Percebe-se que nesse escopo, o que se busca é a valorização dos processos de produção do saber docente por meio de um novo modelo de currículo, que conceda ao professor a autonomia para pesquisar a partir da sua prática um modelo que agregue 


\section{RevistAleph}

as implicações históricas, sociais, econômicas e políticas da atividade de ensinar. Entretanto, há que se buscar as condições para o professor refletir, conforme destaca Pimenta (2012, p. 27):

as reflexões sobre a linguagem, os sistemas de valores, os processos de compreensão e a forma que definem conhecimento, constituem quatro elementos fundamentais sem os quais os professores não conseguem mudar a produção do ensino, de forma a fazê-lo segundo ideias de igualdade e justiça (PIMENTA, 2012, P. 27).

Assim, atuar como professor crítico-reflexivo não se reduz à ideia de apenas valorizar a prática, pois cairia no risco de majorar a experiência em detrimento da ciência - o saber sábio. O que de fato se busca é o equilíbrio entre academia e prática docente, conforme Pimenta (2012, p. 28) esclarece, "o saber docente não é formado apenas da prática, sendo também nutrido pelas teorias da educação". Dessa forma, o conjunto de construtos teóricos são os alicerces na formação dos docentes, pois dotam os professores de concepções epistemológicas para que compreendam os contextos históricos, sociais, culturais, organizacionais e pessoais para formularem os cenários ideais no exercício profissional.

A formação adequada dará aos educadores a segurança necessária para mediar o processo de ensino aprendizagem do aluno. Todavia, não existe um manual para lidar com diferentes deficiências. Nesse sentido citamos Mantoan (2005) ao afirmar que:

a inclusão não prevê a utilização de práticas de ensino escolar específicas para esta ou aquela deficiência e/ou dificuldade de aprender. Os alunos aprendem nos seus limites e se o ensino for, de fato, de boa qualidade, o professor levará em conta esses limites e explorará convenientemente as possibilidades de cada um. (MANTOAN, 2005, p.67).

No entanto, o professor crítico-reflexivo é aquele agente fundamental na promoção da rede de apoio e da equipe pedagógica inclusiva que terá a sensibilidade e atenção de promover atividades pedagógicas variadas, caso a caso, para promover aprendizagens cooperativas e colaborativas. Em nosso ponto de vista, é fundamental que o docente passe por um processo crítico-reflexivo de qualificação que o habilite a pensar o contexto, os problemas, os dilemas e as implicações sociais de sua própria 


\section{RevistAleph}

prática profissional, propondo, experimentando e avaliando, continuamente, alternativas que façam dela um espaço inclusivo. Sendo assim, esse ator pode incorporar a teoria como ferramenta na mobilização de novos conhecimentos capazes de instigálo na articulação coletiva dos saberes da prática, ao mesmo tempo em que os ressignifica e é por eles ressignificado.

\section{Materiais e Métodos}

A pesquisa foi realizada em um município de Minas Gerais, da região da Zona da Mata. Participaram dezoito $(n=18)$ professores atuantes com alunos público-alvo da Educação Especial inclusiva em alguma rede no município. A atuação na modalidade de APD não foi considerada como critério de inclusão/exclusão de sujeitos.

Para o alcance do objetivo da investigação, adotou-se um modelo metodológico organizado em etapas sequenciais de diagnóstico, intervenção e avaliação, conforme a Figura no 1 :

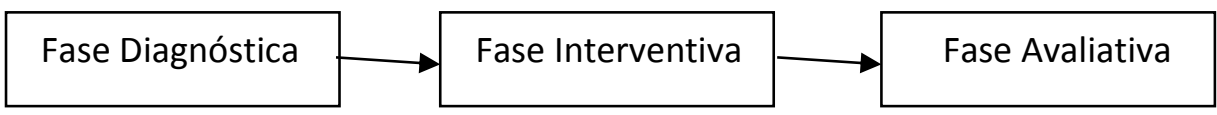

Figura 1: Desenho metodológico do estudo

Com efeito, a oferta do minicurso sobre o APD aos participantes foi a intervenção pretendida. Como forma de mapear perfis pessoais-profissionais, informações e conhecimentos prévios dos sujeitos, foi empreendida a fase diagnóstica. Por outro lado, para identificar efeitos da realização da dinâmica nas impressões dos atores acerca dessa modalidade de ensino, o estudo envolveu, ainda, uma etapa avaliativa. Procurou-se, assim, realizar um minicurso sobre o Atendimento Pedagógico Domiciliar como um campo inclusivo a partir de impressões dos participantes sobre essa modalidade de ensino e avaliar impactos da dinâmica empreendida em suas perspectivas sobre esse exercício profissional.

Na etapa diagnóstica, foi aplicado um questionário aos participantes composto por onze questões, para preenchimento via plataforma Google Docs. O instrumento teve a peculiaridade de reunir pré e pós-teste, diagnóstico e avaliação. Antes do 


\section{RevistAleph}

minicurso, o formulário somente podia ser respondido até a sétima questão. As questões restantes estavam disponíveis para resposta após a atividade, na fase avaliativa do estudo.

Estas foram as temáticas abordadas no questionário aplicado:

(1) Gênero;

(2) Faixa etária;

(3) Formação acadêmica;

(4) Vínculo institucional profissional;

(5) Conhecimento sobre a política nacional do APD;

(6) Identificação de política voltada ao APD na rede educacional onde atua;

(7) Experiência prévia no APD;

(8) Opinião sobre o APD;

(9) Proposições para o desenvolvimento do APD;

(10) Interesse em atuar como mediador/a do APD e

(11) Comentários livres.

Registrado o projeto na Plataforma Brasil, obtido o consentimento das autoridades competentes e dos sujeitos envolvidos, mediante assinatura de Termo de Consentimento Livre e Esclarecido - TCLE, e garantido seu anonimato, foram empreendidas as fases da investigação. O percurso metodológico alavancou resultados, problematizações e conclusões significativas que serão abordadas na próxima seção.

\section{Intervenção crítico-reflexiva na formação de professores}

Na fase diagnóstica, foi realizada uma identificação dos perfis dos participantes e do estado de seu conhecimento sobre o APD, previamente ao minicurso. Por meio de questionário eletrônico, solicitou-se que os sujeitos respondessem sete questões. Foram obtidos os resultados expostos nos Gráficos 1 a 7, que se seguem: 


\section{RevistAleph}

\section{1--GÊNERO}

18 respostas

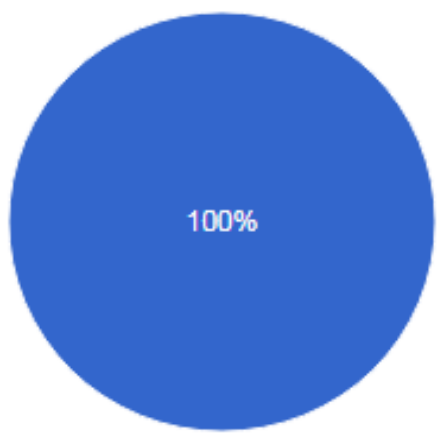

Gráfico 1. Gênero das Entrevistadas

\section{2 - FAIXA ETÁRIA DAS PARTICIPANTES}

Gráfico 2: Faixa etária dos Participantes

\section{3- FORMAÇÃO ACADÊMICA}

Gráfico 3. Formação acadêmica

\section{8 respostas}

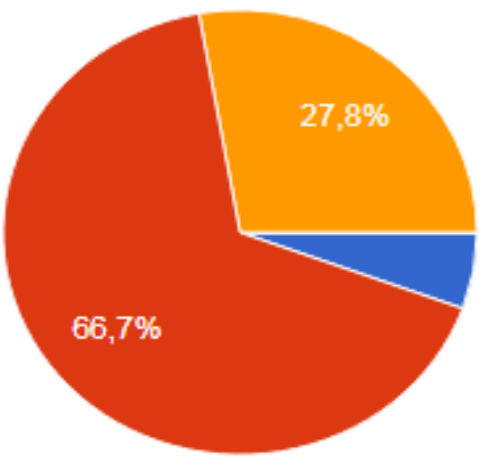

ENTRE 18 a 24 ANOS

Graduação

Especialização

Mestrado

Doutorado 


\section{RevistAleph}

04 - VÍNCULO INSTITUCIONAL

Gráfico 4. Vínculo Institucional

18 respostas

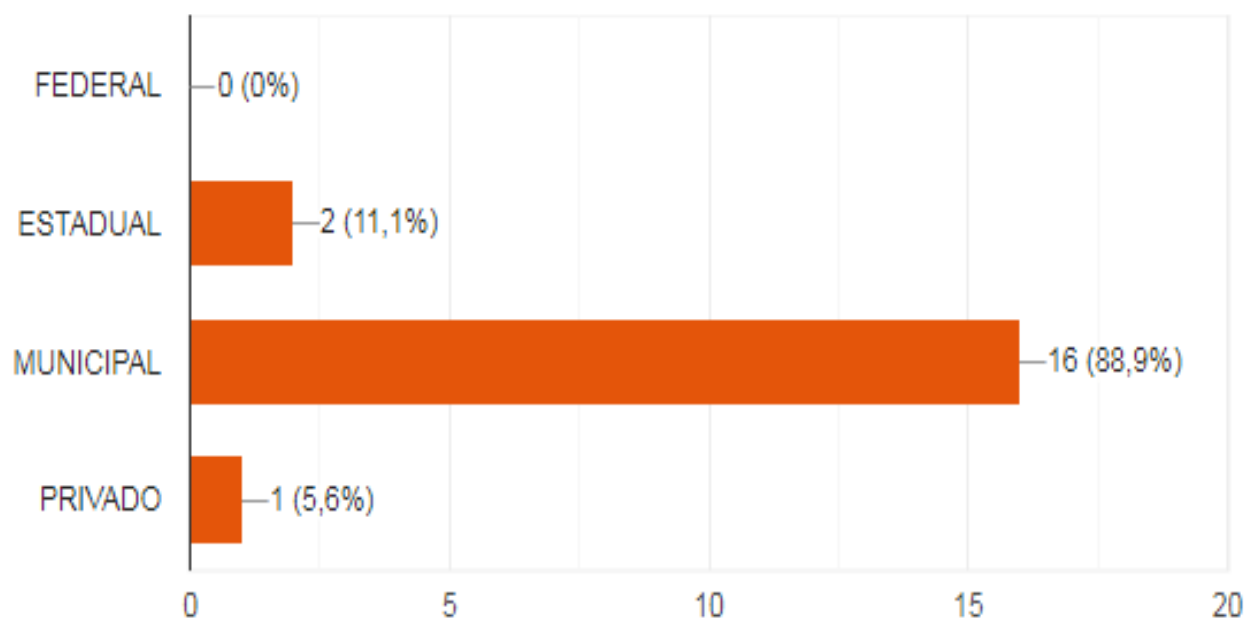

05- VOCÊ TEM CONHECIMENTO SOBRE A POLÍTICA PÚBLICA NACIONAL DO ATENDIMENTO PEDAGÓGICO DOMICILIAR E HOSPITALAR (APD)?

18 respostas

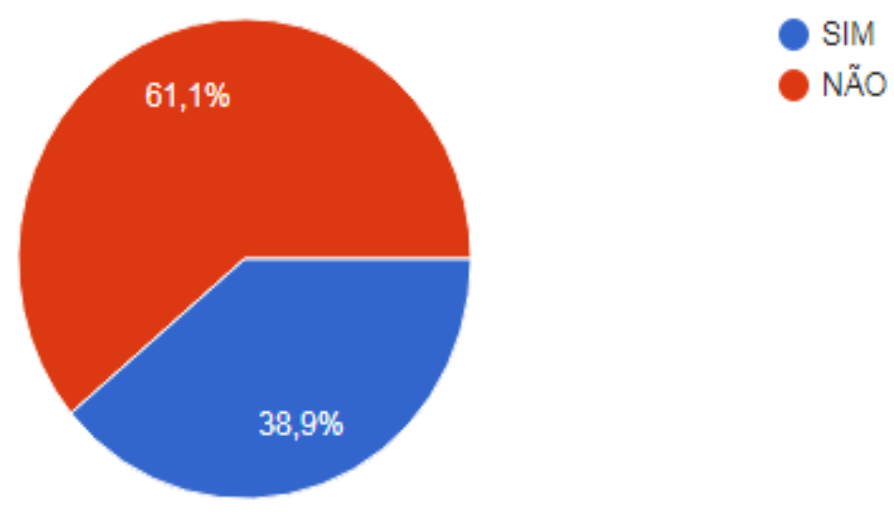

Gráfico 5. Conhecimento sobre política sobre pública nacional do atendimento domiciliar e hospitalar. 


\section{RevistAleph}

\section{6- EM SUA REDE DE ATUAÇÃO (FEDERAL, ESTADUAL, MUNICIPAL, PRIVADA), HÁ ALGUMA POLÍTICA DIRECIONADA AO ATENDIMENTO PEDAGÓGICO DOMICILIAR E HOSPITALAR (APD)?}

18 respostas

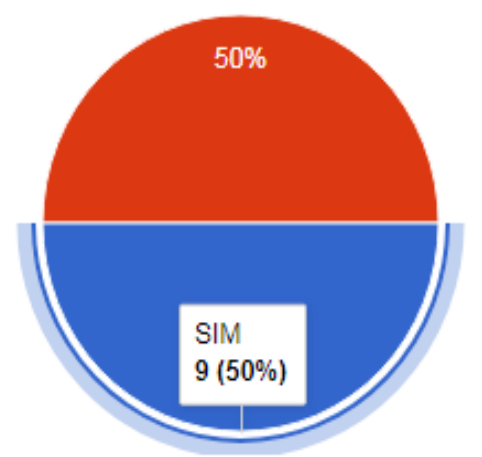

NÃO

Gráfico 6. Conhecimento dos participantes sobre a existência de políticas direcionadas ao Atendimento Pedagógico Domiciliar.

\section{7- VOCÊ TEM ALGUMA EXPERIÊNCIA NO ATENDIMENTO PEDAGÓGICO DOMICILIAR E HOSPITALAR (APD)?}

18 respostas

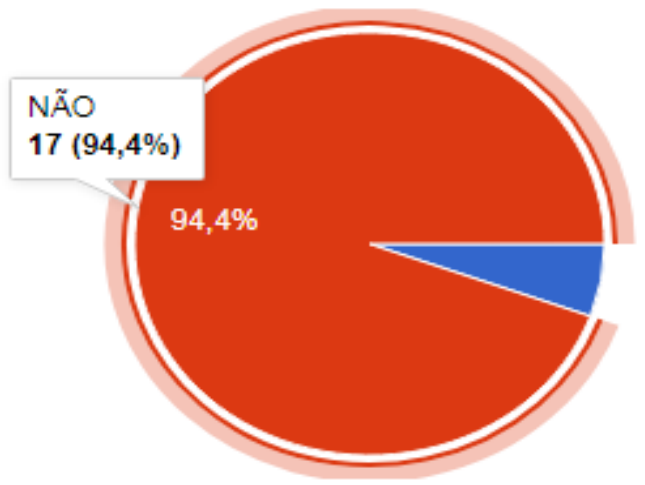

Gráfico 7. Experiência prévia no APD

Em síntese, o survey aplicado revelou que o minicurso seria oferecido a um público feminino, de faixa etária diversificada, majoritariamente com formação no nível de Especialização, atuante na própria rede municipal de ensino e sem experiência no APD - somente uma professora tinha atuado no programa. Outro aspecto importante foi o conhecimento acerca das políticas voltadas ao APD, que dividiu o grupo. É significativo que nove professoras da escola básica não saibam sobre a política de APD 


\section{RevistAleph}

vigente em sua própria rede de ensino, uma política regulada por diretrizes normativas nada recentes.

Organizou-se, assim, o minicurso proposto, considerando estes perfis e o cenário de significativa falta de informação e experiência quanto ao APD. A atividade se iniciou com um slide da psiquiatra Dra. Nise da Silveira - "Para navegar contra a corrente são necessárias condições raras: espírito de aventura, coragem, perseverança e paixão." Passou-se a uma exposição das prerrogativas legais acerca do tema a partir de 1969, e distribuído material aos participantes. Foram explicitados o objetivo e funções do APD, como funciona e qual a legislação vigente na rede municipal de ensino básico.

Durante o minicurso foi abordada a importância da articulação que é o motivo da nossa investigação. O termo articulação foi utilizado inicialmente na literatura marxista para designar as formas pelas quais diferentes modos de produção se combinam numa mesma formação social. Ao longo do tempo o termo ampliou-se para referir-se também às formas pelas quais diferentes dimensões sociais se combinam, numa determinada situação social, para produzir certos resultados. Por exemplo, os Estudos Culturais analisam como raça, gênero e classe social se articulam para produzir estruturas particulares de dominação e subordinação. Algo semelhante ocorre quanto à dinâmica das deficiências na sociedade, campo de exclusões que é significativamente permeado pelas desigualdades sociais. Entretanto, pensando a ideia de articulação num outro sentido, é extremamente importante a vinculação entre as práticas profissionais nas turmas regulares e as práticas profissionais no APD, visto que a proposta pedagógica a ser seguida neste espaço não pode ser muito diferenciada da turma referência do aluno.

Outro ponto da nossa abordagem foi o pensar interdisciplinar e multidisciplinar. Para tanto, foi proposto ao grupo que elaborasse atividades correspondentes à faixa etária dos alunos atendidos. É importante que seja efetiva a inclusão desses alunos no ambiente escolar através da aplicação das mesmas atividades que podem ser feitas nos dois ambientes, a sala de aula ou a residência da criança.

Também foram apresentadas as Propostas Curriculares da Rede Municipal de Ensino, disciplinas Português e Matemática. Explicamos que é fácil obter o material de 


\section{RevistAleph}

todas as disciplinas e imprimi-las através do acesso à internet. Essas propostas foram construídas coletivamente por profissionais do município no ano de 2012 por meio de estudos nas escolas e indicação de grupos representativos e apresentações num seminário.

Com o objetivo de trabalhar as capacidades de linguagem em torno de um gênero textual, Schneuwly e Dolz (2010), organizaram os gêneros em cinco agrupamentos, tendo em vista uma didática de ensino/aprendizagem da língua. Os agrupamentos são: narrar, relatar, argumentar, expor e descrever ações. Entregamos cópia do quadro 2, retirada da Proposta Curricular de Língua Portuguesa, PJF (páginas 19 e 20). Posteriormente, trabalhamos os gêneros do discurso: cruzamentos possíveis em uma perspectiva interdisciplinar - Poesia TARDE NUMA PRAÇA, portador de texto foi um jornal, enfatizando o pensar interdisciplinar e multidisciplinar.

Visando trabalhar a Proposta Curricular de Matemática, da Rede Municipal de Ensino, foi distribuído material concreto em madeira: Régua de Frações e solicitado que formassem grupos com o intuito de elaborar atividades que pudessem ser aplicadas de acordo com a faixa etária dos alunos que eles trabalham.

Para finalizar o minicurso, o propósito foi enfatizar a importância da "criatividade para desenvolvimento emocional e intelectual do aluno". Foi proposto ao grupo uma dinâmica. Nesse momento, entregamos um pacotinho contendo um brinquedo - bat bag- a todos os participantes, texto instrucional da embalagem. Ao fundo, a música Brincadeira de Roda (Maria Rita).

Pode-se compreender, na fase avaliativa, que o minicurso foi muito produtivo, alcançando nossos objetivos quanto à informação dos sujeitos sobre o APD e o entendimento da sua relevância no cenário de uma educação escolar inclusiva. Nesse momento, a ideia da articulação entre os trabalhos das salas de aulas regulares e do APD esteve em destaque. Alguns depoimentos convergem a essa direção, tais como:

- A articulação é um momento muito importante, pois todos os professores precisam estar envolvidos para que o aluno de fato seja atendido em suas necessidades (Entrevistada 1).

- um momento muito importante porém, ainda é necessário ampliar a política de formação continuada para que os professores possam 


\section{RevistAleph}

assumir de fato seu papel nessa articulação (Entrevistada 2).

- a articulação entre o APD e a sala regular é uma iniciativa importante para o desenvolvimento do aluno (Entrevistada 3).

O conceito de articulação presente nas citações acima sugere as ideias de trabalho em equipe e rede de apoio, dois pilares da educação inclusiva. Não se pode promover um ensino como tal de forma individualista, mas sempre comunitarista. Como afirma o casal Stainback (1999),

[...]Trabalhando juntos, alunos, professores e pais podem criar comunidades escolares que contribuam mais para a educação de todos, exatamente porque se envolvem abertamente em problemas relacionados às dificuldades humanas e em incertezas que são facilmente mascaradas pela rotina escolar (STAINBACK; STAINBACK, $p$. 61).

As perguntas a partir da Questão 8 foram realizadas apenas no pós-teste. Nesse momento foi perguntado "qual é a sua opinião sobre o atendimento pedagógico domiciliar e hospitalar (APD) como uma política pública?". Os termos mais mencionados seguem na figura 2, em ordem de recorrência:

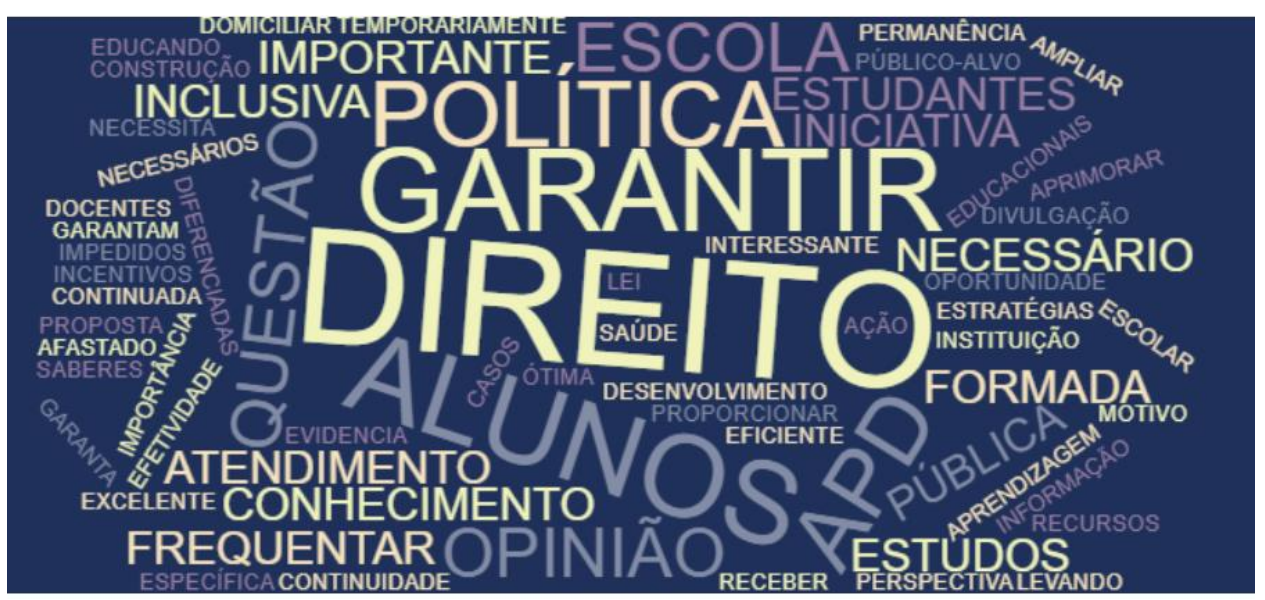

Figura 2. Nuvem de palavras construída a partir da pergunta "qual é a sua opinião sobre o atendimento pedagógico domiciliar e hospitalar (APD) como uma política pública?"

As palavras em maior evidência são direito, APD, alunos, garantir, política, atendimento, conhecimento, estudos. Chama a atenção, nesse momento, a presença pouco marcante da palavra "inclusão" e de conceitos pertinentes às suas dimensões organizacional, procedimental e pedagógica. "Aprendizagem", por exemplo, teve uma aparição bastante discreta. 


\section{RevistAleph}

A Questão 9 analisou-se a opinião das entrevistadas sobre a organização do APD. A pergunta foi: "Em sua opinião, como deve ser organizado o atendimento pedagógico domiciliar e hospitalar (APD)?"

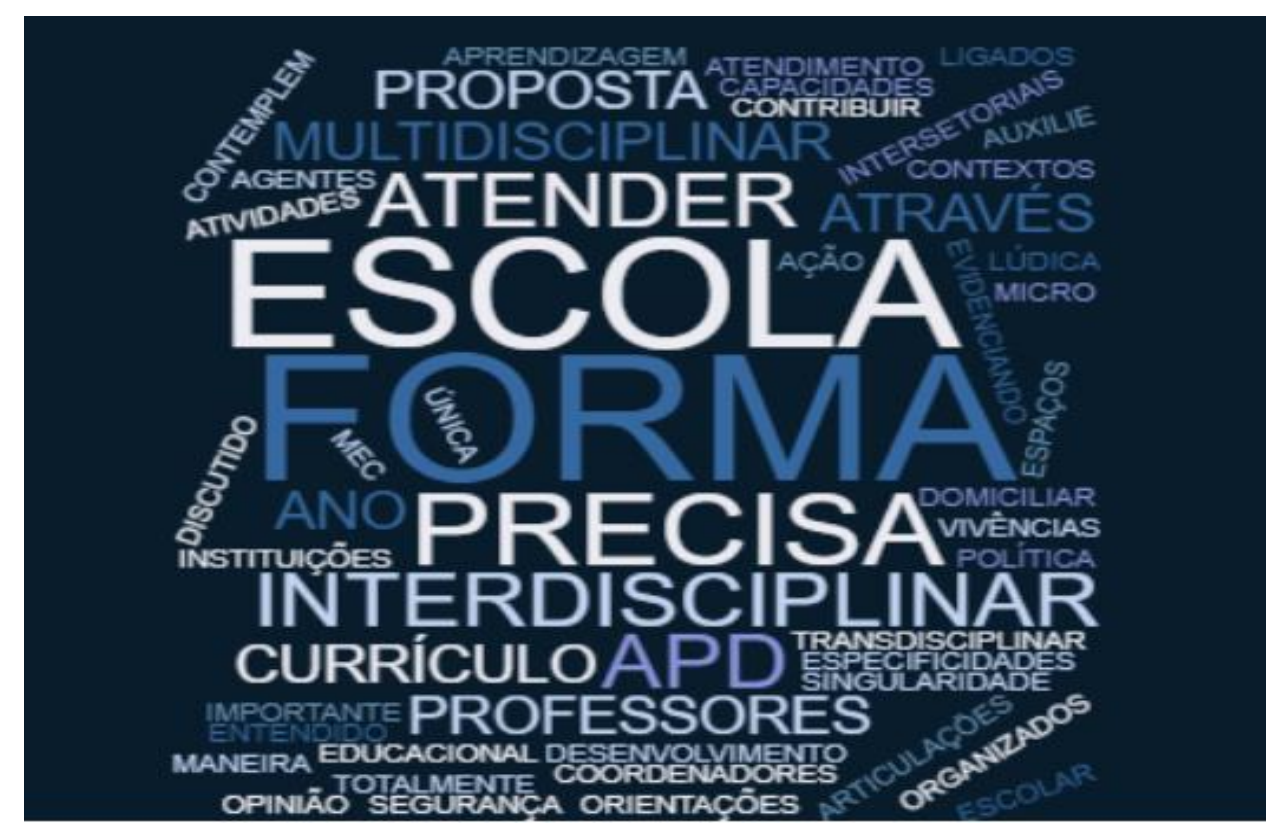

Figura 3. Nuvem de palavras construída a partir da pergunta“Em sua opinião, como deve ser organizado o atendimento pedagógico domiciliar e hospitalar (APD)?"

As entrevistadas relataram que o APD é uma forma de atendimento que deve ser organizada pela escola, em conjunto com professores e coordenadores. Foi consenso que a proposta deve ser interdisciplinar, multidisciplinar e transdisciplinar, através de articulações intersetoriais em todos os espaços da escola e fora dela. Ainda foi explicitado que deve ser organizado conforme as orientações do MEC de acordo com a proposta curricular da escola e do ano em o aluno está matriculado. Merece destaque também a importância do conhecimento sobre o aluno e suas singularidades buscando o desenvolvimento de práticas pedagógicas que as contemplem.

Na questão 10 buscamos saber o interesse das participantes em desenvolver o trabalho com o atendimento de alunos, seja domiciliar ou hospitalar (Gráfico 8): 


\section{RevistAleph}

\section{QUESTÃO 10: VOCÊ TEM INTERESSE DE ATUAR COMO MEDIADORA DO ATENDIMENTO PEDAGÓGICO DOMICILIAR E HOSPITALAR (APD)?}

18 respostas

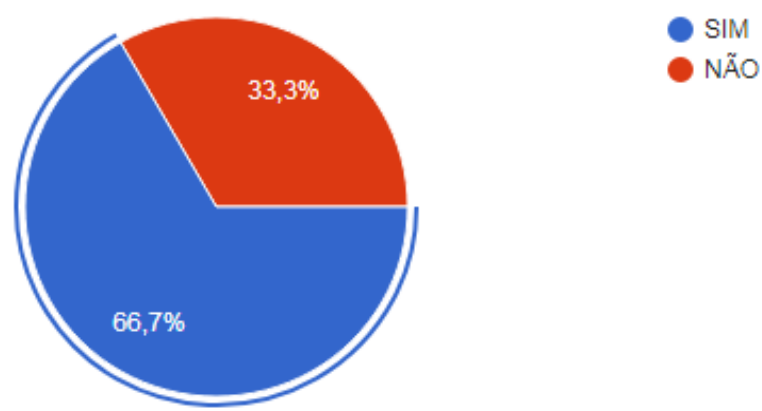

Gráfico8: Interesse das participantes em atuar como mediadora do Atendimento Pedagógico Domiciliar e Hospitalar (APD)

$\mathrm{Na}$ sequência, as professoras registraram seus comentários livres sobre o minicurso e o APD como possibilidade educativa, conforme a seguinte "nuvem de palavras":

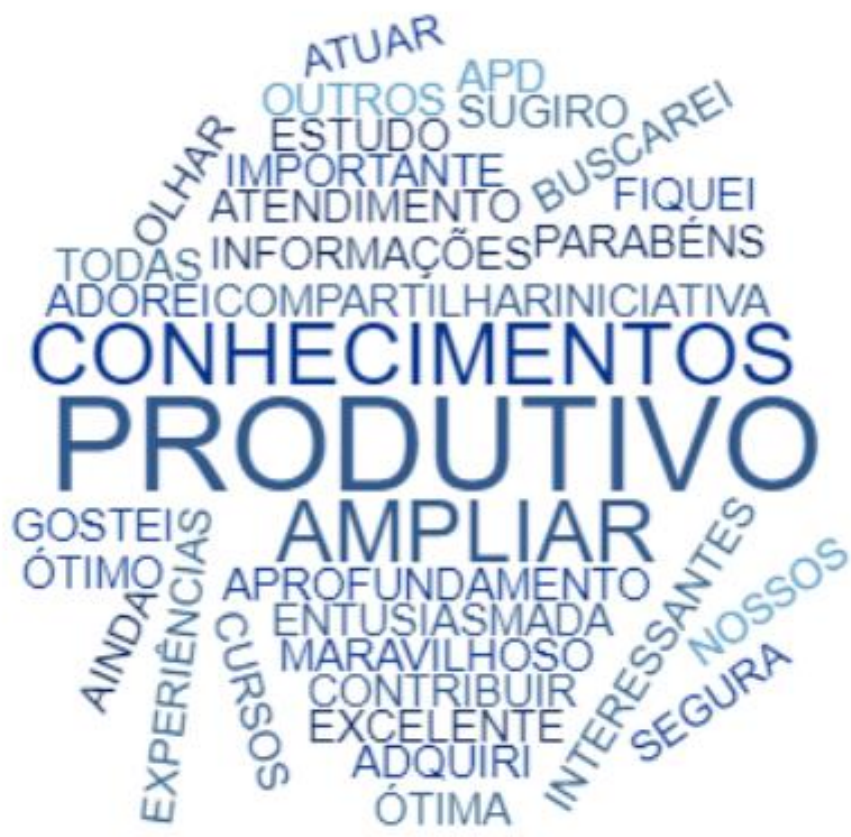

Figura 4. Comentários livres.

Em geral, as participantes consideraram o curso bastante produtivo, uma experiência de construção de conhecimento e de ampliação e aprofundamento de perspectivas quanto à sua profissão. Observamos um consenso do APD como direito do 


\section{RevistAleph}

aluno que está impedido de frequentar a escola, por motivos de saúde. Averiguamos uma significativa vontade de atuação na área do APD, manifestada por 16 participantes. Conforme pode ser observado na imagem acima os sujeitos de modo geral, relataram a necessidade de formação para que efetivamente possam atuar nesse tipo de atendimento. É importante ressaltar que, apesar de um terço das professoras não terem manifestado interesse em atuar no APD, em quase todas as respostas, verificamos que o minicurso proposto serviu como fonte de informação e estímulo aos sujeitos para que continuem estudando sobre o tema.

O acesso do aluno alvo do APD, sem dúvida, é uma plataforma políticopedagógica de caráter inclusivo e as participantes não discordam disso. Entretanto, cabe pontura que o minicurso revela uma apropriação ainda assistemática e pouco aprofundada do conceito de inclusão (Queiroz, 2018; Stainback e Stainback, 1999). Falase em articulação, interdisciplinaridade, ampliação de horizontes e garantia de direitos. Contudo, houve uma patente escassez de apontamentos quanto à dimensão pedagógica da inclusão: a aprendizagem colaborativa. Sem esse fator, como viabilizar redes de apoio e trabalhos em equipe realmente inclusivos? É nesse cenário que uma formação profissional desempenha papel vital para promover mudanças efetivas em favor da inclusão.

A análise dos questionários mostrou-nos que os participantes consideram, mesmo que através de um discurso pouco amparado pela teoria, a perspectiva da educação inclusiva como um direito do aluno e têm consciência da existência de uma legislação que garante ao aluno acamado de dar continuidade na sua formação escolar, porém a maioria não tem experiência nesse tipo de atendimento. Observamos também que a maioria dos participantes tem interesse em desenvolver um trabalho com esse alunado. Destacamos, durante o minicurso, porém, que a maioria dos entrevistados sente-se insegura e cita a formação deficiente para lidar com a inclusão. É nesse campo que a reflexividade crítica se faz fundamental como princípio norteador de uma qualificação profissional que possa responder ao desafio. 


\section{RevistAleph}

\section{Discussão}

Para uma abordagem mais aprofundada dos achados, nada mais apropriado e construtivo do que retomar as categorias de análise decorrentes de nossa fundamentação teórica sobre a educação inclusiva e a docência crítico-reflexiva. À luz desses aspectos, podemos refletir acerca de algumas linhas fundamentais de análise em torno do APD como um campo inclusivo e crítico-reflexivo:

(1) A educação inclusiva e suas características;

(2) A insegurança dos profissionais em trabalhar à luz da educação inclusiva;

(2) A criatividade do professor na proposição de alternativas pedagógicas inclusivas e

(3) A necessidade de um trabalho pedagógico coletivo e de uma rede de apoio que envolva escola, família e sociedade em prol de um ensino como tal.

Aprendizagens cooperativas e colaborativas dependem de vários fatores: o professor precisa de tempo para conhecer seus alunos, suas competências, suas necessidades educacionais específicas e possíveis formas de aprendizagem. É preciso reconhecer que cada aluno pertence ao grupo dependerá da comunicação e da interação eficaz entre professor-aluno, aluno-aluno, assim como da observação constante durante todo o processo de aprendizagem.

Redes de apoio e trabalho em equipe são fundamentais à educação inclusiva. Para STAINBACK e STAINBACK (1999), é necessário o envolvimento da comunidade escolar como um todo para que a inclusão seja efetiva, e quando há esse envolvimento vemos os efeitos positivos da inclusão na renovação da escola. Entretanto, segundo os autores tais efeitos só serão percebidos se quando as pessoas envolvidas:

1) percebem discrepâncias entre o que eles querem fazer e o que permitem os atuais limites, relacionamentos e estruturas;

2) adaptam esses limites, relacionamentos e estruturas para possibilitar os próximos passos para a inclusão." (STAINBACK e STAINBACK, 1999, p. 49)

A inclusão de alunos com deficiências severas nas turmas de educação regular eleva a consciência de todos os envolvidos, contudo provoca relações de medo- fruto do despreparo- e defesa. Quanto mais criativos formos, conseguiremos avançar na 


\section{RevistAleph}

elaboração de planejamentos para pessoas com deficiência. Incluir os alunos com deficiências importantes nas turmas de educação regular eleva a consciência de cada aspecto inter-relacionado da escola como uma comunidade: seus limites, os benefícios a seus membros, seus relacionamentos internos, seus relacionamentos com o ambiente externo e sua história.

Para que a renovação da escola efetive-se, profissionais, familiares e alunos inclusivos devem sair da zona de conforto, apropriar-se da força cultural que detêm, capazes de romper os obstáculos enfrentados. Por sua vez, a construção de relações para além da escola será consolidada, transformando a inclusão em força renovadora, ações comportamentais diferentes.

Nesse projeto, o professor crítico-reflexivo tem papel protagônico. Refletindo sobre o que cada contexto educativo demanda, o professor deve mobilizar com criticidade os variados saberes de referência ao seu exercício profissional (escolares, disciplinares, curriculares e experienciais). Se o APD se diferencia do ensino regular por uma série de características, convém que o docente que atua nessa modalidade de ensino proponha alternativas pedagógicas coerentes com as suas necessidades específicas. A partir da análise dos aspectos estruturais dos contextos educativos e particulares de cada situação pedagógica, esse profissional pode, conjuntamente com uma rede social de apoio à escola e a sua equipe pedagógica, experimentar e avaliar continuamente alternativas que favoreçam o aperfeiçoamento do ensino.

Segundo Nóvoa (2001),

O próprio trabalho em equipes pedagógicas pode ser um começo. Se insistirmos na produção de um saber profissional, emergente da prática e de uma reflexão sobre ela, teremos naturalmente uma produção conjunta. Para isso, a escola tem de organizar momentos interdisciplinares de trabalho que não caiam no vazio curricular, mas que promovam uma integração dos conteúdos de várias matérias. (NÓVOA, 2001, s/p).

Nessa direção, Covic e Oliveira (2011) afirmam que:

[...] a escola que atenda a essa demanda não está posta, no entanto, compreendemos que possa acontecer com um processo de aprendizagem por ressignificação de seus espaços, tempos, horizontes, concepções, posições e formação. Ressignificar, 


\section{RevistAleph}

compreendido aqui, como o processo criativo de atribuir novos significados a partir daquele já conhecido, validando um novo olhar sobre o contexto em que o sujeito está imerso. Em termos mais concretos, nessa ação temos o moto mudança/permanência. (COVIC e OLIVEIRA, 2011, p. 27).

Foi nesse espírito de ressignificação que se propôs o minicurso. Ainda que o estudo tenha se materializado numa dimensão bastante restrita, tanto em termos de espaço e tempo quanto de enfoques reflexivos, a organização da atividade respondeu à demanda de informar o professor da educação especial sobre a importância da inclusão e da reflexividade crítica na construção de um APD eficaz, pensado para uma escola realmente humanística.

\section{Considerações Finais}

Retomando o desenho metodológico adotado para o alcance do objetivo do estudo, a análise dos questionários mostrou-nos que os participantes consideram a educação inclusiva como um direito do aluno e têm consciência da existência de uma legislação que garante ao aluno acamado de dar continuidade na sua formação escolar, porém a maioria não tem experiência nesse tipo de atendimento. Observamos também que muitos participantes têm interesse em desenvolver um trabalho com esse alunado. Destacamos que grande número dos entrevistados sente-se insegura e cita a formação deficiente para lidar com a inclusão.

Por isso, é preciso repensar a formação docente, possibilitar que o professor seja reflexivo durante a sua prática. Tal mudança, passa pela discussão da razão de ser professor na atual sociedade, que abre espaço no acolhimento de indivíduos munidos de necessidades distintas e tratamento diferenciado no processo ensino-aprendizagem. Percebe-se que este novo cenário de atuação no contexto escolar, vislumbra para o docente uma oportunidade única de agir com visão crítica, e isso exige romper com procedimentos antigos de tratar todos os aprendizes com igualdade, mas é preciso ir mais além; possibilitar a equidade para atingir essa igualdade. Isso é possível, quando o professor sai da sua zona de conforto e percebe que no ambiente escolar as diferenças só são combatidas com ações e atitudes que realmente rompem com os obstáculos que 


\section{RevistAleph}

causam os limites de aprendizagem nos educandos com deficiências.

Já que promover a formação continuada do professor não é uma tarefa tão simples, porque exige dele aprender a aprender ou aprender a reaprender, e nem sempre os docentes conseguem mobilizar as ferramentas (teorias, situações didáticas, metodologias de pesquisa e ensino) que possibilitam incorporar novos procedimentos em sua prática. Talvez, uma possibilidade é investir na formação inicial do professor, levar para os licenciandos uma proposta que incorpore na sua formação a discussão reflexiva e crítica que contemple as competências e habilidades para atuar no ambiente escolar de diversidade.

Sabemos, evidentemente, das limitações do presente estudo. Ainda assim, esperamos que ele possa contribuir a um lacunar estado da arte sobre uma importante, porém ainda pouco conhecida, modalidade de ensino inclusivo. É preciso informar acerca desse campo e fomentar interesse em atuar nele em programas de formação profissional - inicial e continuada. Redes sociais de apoio e equipes pedagógicas comprometidas com a proposta são igualmente necessárias. Inclusão não é competição e, na educação, ela é a maneira de formarmos seres e comunidades conscientes, mais humanos.

\section{Referências}

BRASIL. Decreto Lei no 1.044/69. Brasília, 1969.

Lei no 6.202/75. Brasília, 1975.

. Constituição da República Federativa do Brasil. Brasília: Imprensa Oficial, 1988.

. Estatuto da Criança e Adolescente, 1990

Lei n. 9394 de 20 de dezembro de 1996. Lei de Diretrizes e Bases da Educação Nacional. Brasília: MEC, 20/12/1996.

Ministério da Educação. Secretaria de Educação Especial. Classe Hospitalar e o atendimento pedagógico domiciliar: estratégias e orientações. Brasília: MEC; SEESP, 2002.

Política Nacional de Educação Especial na perspectiva da Educação Inclusiva. Brasília: MEC/SEESP, 2008.

Secretaria de Educação Especial. Política Nacional de Educação Especial na Perspectiva da Educação Inclusiva. Brasília, DF, jan. 2008. 


\section{RevistAleph}

COVIC, A.N.; OLIVEIRA, F.A.M. O aluno gravemente enfermo. (Coleção Educação e Saúde, v. 2), São Paulo: Cortez, 2011.

MANTOAN, Maria Teresa Eglér. Caminhos Pedagógicos da Educação Inclusiva. In: GAIO, R.; MENEGUETTI, R.G.K. Caminhos Pedagógicos da Educação Especial. 3.ed. Petrópolis, RJ: Vozes, 2005.

. Inclusão Escolar: O que é? Por quê? Como fazer? 2.ed. São Paulo: Moderna, 2005.

NÓVOA, Antonio. Antonio Novoa: "professor se forma na escola" (Entrevista concedida a Paola Gentile em 01 de maio de 2001). Disponível em:

$<$ https://novaescola.org.br/conteudo/179/entrevista-formacao-antonio-novoa $>$. Acesso em: 14 mar. 2019.

PETERS, Itamara. Ebook Atendimento Educacional em Ambiente Hospitalar e DomiciliarMódulo 1 - Secretaria Especial à Distância de Formação de Professores (SEDFOR) - UFMS, 2019.

PETERS, Itamara. Ebook Atendimento Educacional em Ambiente Domiciliar - Módulo 3 Secretaria Especial à Distância de Formação de Professores (SEDFOR) - UFMS, 2019.

PIMENTA, Selma Garrido. Professor reflexivo: construindo uma crítica: In: PIMENTA, Selma Garrido, GHEDIN, Evandro (Orgs). Professor reflexivo no Brasil - gênese e crítica de um conceito. São Paulo: Cortez, 2012.

PIMENTA, Selma Garrido, GHEDIN, Evandro (Orgs). Professor reflexivo no Brasil - gênese e crítica de um conceito. São Paulo: Cortez, 2012.

QUEIROZ, P. P. Ensino, Saúde e Inclusão: olhares e reflexões. Rio de Janeiro: Autografia. 2018.

SALLA, Helma. O Atendimento Pedagógico Domiciliar de alunos que não podem frequentar fisicamente a escola: o caso do Distrito Federal. Mestrado Profissional em Ensino de Ciências (PPGEC) da Universidade Estadual de Goiás (UEG), Campus de Anápolis de Ciências Exatas e Tecnológicas - Anápolis - Goiás, 2017.

SCHÖN, Donald. The reflective practitioner. Nova York: Basic Books, 2000.

STAINBACK, Susan; STAINBACK, Willian. Inclusão: Um guia para educadores.Porto Alegre. Artmed, 1999.

TARDIF, Maurice. Saberes Docentes e Formação Profissional. Petrópolis: Vozes, 2010.

Data do envio: $15 / 07 / 2019$

Data do aceite: $13 / 12 / 2019$. 